\title{
THE IMPACT OF THE INFORMATION REVOLUTION ON RAISING THE CHILDREN OF HOUSING INSTITUTIONS IN ROMANIA
}

\author{
Mona BĂDOI-HAMMAMI ${ }^{1}$ \\ Corina COLAREZA2 \\ Luciana MIHAI ${ }^{3}$ \\ DOI: 10.35782/JCPP.2019.4.06
}

\begin{abstract}
We live in a time of speed, when everything is rapidly changing around us. Not long ago, mobile devices were fiction, and we would only see them in movies, while here we are now, living in a period of voice and video calls through a 'mobile phone' device. This device represents a real technical revolution, especially through the modern applications that open up - for us and our children - areas that were difficult to access earlier, such as science, sports and other, more negative media, like pornography sites. We have been able to easily segment and categorize search engines, but how could we classify social networking sites and apps? It is difficult to say whether they are bad or good, the reason for this being that the problem is not in its programming but in its users. Children are in danger because of the Information Revolution we are experiencing, especially two categories of them - the first category includes children of families where parents work for a long time, both or one of them, or those missing from home for a significant period of time. In this category, parents may sometimes avoid mistakes by addressing the danger to their children and thus protecting them, while the second category includes orphaned and abandoned children, or children that for various reasons find themselves in social protection centers and do not benefit from any such protection. These mentally and physically healthy children, due to their presence in these centers, are vulnerable, and we can diagnose them with a special sort of disease ('social centralization complex') because they suffer psychologically from their abandonment, their presence in these centers and the absence of adoptive chances. Regardless of the quality of the services offered in said placement centers, this mental complex remains, which creates a weak point with a profound impact on the rest of the lives of the respective children. To overcome their reality, children rebel against everything that surrounds them, and if they can conceal reality, then they do so by any means necessary. Due to the facts that these children do not have a strong educational
\end{abstract}

${ }^{1} \mathrm{PhD}$ student at the University of Bucharest, Faculty of Psychology and Education Sciences. Doctoral School of Psychology and Education Sciences. E-mail: mona10bd@yahoo.com

$2 \mathrm{PhD}$ student at the University of Bucharest, Faculty of Psychology and Education Sciences. Doctoral School of Psychology and Education Sciences. E-mail: corinacolareza@yahoo.com

${ }^{3} \mathrm{PhD}$ student at the University of Bucharest, Faculty of Psychology and Education Sciences. Doctoral School of Psychology and Education Sciences. E-mail: luciana.mihai@upb.ro 
base and that it is difficult to compensate for their lack of a familial atmosphere, the impact of the Information Revolution on them is strong, and trying to find solutions in order to avoid or correct the negative effects in various personal areas is a necessity.

Keywords: information revolution; housing institutions; placement centers; electronic learning methods; abandoned children

\section{Introduction}

This paper aims to study the impact of the Information Revolution on institutionalized children's education, health and way of thinking. The article develops in two directions. The first is to emphasize that we are normally born with a family that takes care of us biologically and socially for much longer than the rest of the living beings that we might encounter. Childhood is important to us because it affects all aspects of our lives as adults. We live within societies that each have their own customs, traditions, and institutions. Our ability to curb our instincts and act in a civil way is what allows us to live in harmony with each other and with other creatures, so any dysfunctionality that may appear in a family is a real danger to society. The second direction of the article is to establish reasons with theoretical and methodological grounds for the study application.

One of the predominant aspects of the times that we live in is the spread of the phenomenon of family disintegration, which coincides with our transition from diverse societies to a singular virtual society. Opinions differ on the reason for the increase in the number of families that are disintegrating. The reasons are diverse and include the possibility of womens' employment in a vast number of work sectors, economic insecurity or the absence of one or both parents within the family. Unfortunately, all these factors can only be seen as secondary elements of the outbreak of this phenomenon, compared to the absence of a strict social system and laws that would oblige parents to care for their children and their families in the best possible way.

Both the number of children benefiting from the services of social institutions, as well as that of children belonging to disintegrated families are large. Consequently, there are lots of children who lack a family as their most important source of guidance, which makes them vulnerable to delinquency and to the negative effects of the virtual world. Therefore, it is important to limit the different effects of the Information Revolution on children in housing institutions because they lack any sort of real guidance and evaluation elements other than the respective social institutions in order to direct them towards their own interests and the interests of the wider society. 


\section{Theoretical Background}

\section{IT Revolution}

The word 'revolution' is used to describe a change in the fundamental construction of society. The Information Revolution witnessed nowadays is linked to the birth of the digital world and the continuous qualitative development in networks and information systems and technologies, in addition to the further development of industries tied to pop culture, such as the direct satellite broadcasting. The modern society is being characterized by an explosive expansion of information, which has been generated and accumulated in such short periods of time that humans seem incapable to efficiently cope with.

We can compare the transition brought upon by the Information Revolution with the shift from an agricultural to an industrial society. It is a revolution that transcends ideologies and eliminates national borders in order to build a mental system through communication. The technological development created by the human mind has become an important element in the flow of knowledge. It has even greatly contributed to the development of the human mind itself. A specific definition of the Information Revolution cannot be formulated, but Odeh (2013) offers some basic elements of this concept - the emergence of an international community environment based on the selection of information, knowledge, and communication, through the creation of an effective and organized relationship between man and other things, as follows:

- Man and the state;

- The state and the environment;

- Various societies without regard to geographical boundaries, religion, language or ideology.

The biorhythmic course that aims to clarify the relationship between society and its people includes the latters' physical, emotional, intellectual and intuitive characteristics (prediction), as well as the freedom to receive market information and knowledge, removing and overcoming geographical barriers between nations, countries and peoples. The Information Revolution is an important historical event in human life, which has led to the emergence of a productive system of wealth primarily based on the human mind, and not on machines or muscle power. Knowledge is the key to economic growth and development in the 21 st century. The revolution of modern communication technologies has thus overcome both time and space.

The era of the Information Revolution has several features and characteristics that distinguish it from other ages, such as:

- The control of information in various areas of life;

- The economy and security of countries are based on the information industry;

- Acquisition of information and the marketing of goods and services; 
- The exploitation of human thought through the conduct of intellectual analyses, studies and scientific research in addition to the continuous development of mechanisms in order to cope with the different requirements of life;

- An increased investment in modern technologies such as communications, electronics, computers, and a high degree of inter-operability through their regular integration;

- Ease of dealing with computers and their use in various areas of military, economic, political, cultural and social life;

- The significant increase in the flow and production of information;

- The spread of networks overlaps significantly, due to their transformation from local to regional and global networks.

The Information Revolution and the spread of technology have greatly influenced social life. Some of the most impactful aspects are (Badrawi, 2003: 319-321):

a) Social Structure: The emergence of the information and communication revolution has created a gap between two categories of society:

- The category that owns, uses and trades information;

- The category that does not have the information and finds it difficult to use and circulate it.

This gap widens with the increasing impact of the large amount of information produced and with the widespread means of communication available. The Information Revolution has also affected the participation of women in society. Their participation and personal development have increased in services, information, and communications. The impact of the revolution is not limited to the social structure of the time period. Information technology has changed the perception of people with special needs as well, particularly in relation to their ability to participate effectively in society.

b) Violation of the principle of equal opportunity: The production and use of information technologies have contributed to the reduction of equal opportunities. The Information Revolution has led to disparities in opportunities between individuals and communities. While the general wealth has increased, the poor have grown poorer, affecting the quality of lifestyles and jobs, as well as incomes and livelihoods.

c) The tremendous growth in information volume and the speed of its spread: The accumulation of knowledge began in the late twentieth century due to the increase of the level of information and the emergence of many new sciences. Over time, the flow of knowledge has continuously increased and, as a result, the production of books and documents of various types has also risen.

d) The growing sense of alienation: The rapid transformation and constant change in economics have led to a significant change in the nature of jobs and professions, with the emergence of new jobs. As a result, some individuals have been forced to 
100 | The impact of the information revolution on raising the children of housing institutions

further diversify their skills in order to keep up with those rapid changes. Some of them have lost their job or have been forced to change it. This has led to a reduction in the positive societal participation of individuals and the increase of unemployment rates. This causes the individual to create a kind of comparison between their society and other societies, with a negative effect on morale.

\section{Abandoned children}

Children described as "abandoned" lack family care for the following reasons:

- The death of one or both parents and the absence of other relatives who could care for them;

- The family's lack of economic and health conditions that would allow it to support and raise children;

- Parents may be exposed to health problems (disability);

- Addictions of almost any kind.

When one or more of these reasons is true, the state will include such children in housing establishments after checking that there are no relatives who can take care of them at that time. These institutions allow persons up to the age of 26 to live there and benefit from various services, such as:

Housing institutions/placement centers: Government or community institutions that shelter children deprived of family care. The children are categorized within the shelter institution according to age, gender and sometimes school year. Each group is supervised by educators and psychologists as well as specialized medical personnel who cares for the childrens' health.

$>$ Electronic learning methods: E-learning means the employment of IT\&C solutions to assist education with an ultimate goal of performance enhancement. Using informatics in learning allows the gathering of knowledge in a beneficial and fun way. Pedagogical methods (simultaneous and asynchronous) have to be adapted in order to meet the need for the rapid acquisition of information.

Through personal observation and previous studies on sheltered children, a similarity was observed regarding the structure of social enterprises in Romania and those in third world countries. We noticed similar behavioral problems experienced by abandoned children in most countries of the World. The most important problems - serious emotional disorders that must be acted upon - identified are:

- Theft, which can appear at early ages (starting with 4 years of age). Unless remedial action is taken to prevent it from developing, theft can develop over a long course of years;

- Lying;

- Aggressive behavior;

- Hyperactivity;

- The so-called "laws of the jungle" that dominate human actions and everyday situations. 


\section{Methodology}

The importance of this research stems from the fact that we live in an era of speed; the rapid development of technology that has affected not only our lives but, in particular, the lives of institutionalized children, whose ability to distinguish between good and evil is weak. Adding to this that such children are passionate enough to follow the latest trends, IT\&C development can result in a danger unless properly managed.

This research has studied the impact of the Information Revolution on institutionalized children, trying to present solutions to minimize its negative effects (there where these existed) and to protect our society from a potentially turbulent and unstable future generation.

The participation in this study occurred voluntarily as part of a $\mathrm{PhD}$ research paper conducted between 2016 and 2019. Subjects were allowed to withdraw from the project at any time. For participants under the age of 18, their tutors were asked for consent prior to the start of the actual research. The sample consisted of 45 adolescents aged 13 to 21 , both male and female, belonging to two housing/placement centers in Constanta, Romania.

The main research question asked was: How are institutionalized children affected by the Information Revolution? The research started from the assumption that there is a statistically significant relationship between the Information Revolution and the change of institutionalized childrens' educational principles and their behavior. Subsequently, the research hypotheses were:

a. A relationship of statistical significance exists between the decline of educational, health and behavioral standards in children from educational institutions and the Information Revolution;

b. Educational methods based on modern IT\&C technologies exist that can counter and correct the behavioral and educational problems suffered by most children from housing institutions.

To verify the research hypotheses, the following methods have been used:

1. A questionnaire, structured in eight self-administered items;

2. A focus group with eleven participants from the two children housing institutions. This method was used for a more in-depth understanding of the quantitative findings.

The focus group method was used to gather in-depth data on the following:

- The information that institutionalized children have about the Information Revolution;

- The importance of mobile phones and other electronic devices and ways to obtain them;

- Dangers and benefits of available electronic games;

- Time spent on the Internet;

- Friends from the virtual world. 
102 | The impact of the information revolution on raising the children of housing institutions

Several meetings have been held with five groups of adolescents to discuss the aforementioned items. A group consisted of maximum six persons.

3. An interview was conducted with fifteen caregivers (specialized educators who look after the children). They were asked the following questions:

I. What is the impact of the Information Revolution on these children?

II. Do you use modern IT\&C technologies in your profession?

III. What are the most important changes that have aroused your attention regarding a specific product of modern IT\&C technology?

\section{Results}

Table 1 displays the results of the self-administered questionnaire.

Table 1: Results of the self-administered questionnaire

\begin{tabular}{|c|c|c|c|}
\hline No. & The question & Answers & $\begin{array}{c}\text { Frequency } \\
(\mathrm{N} \text { respondents }= \\
45)\end{array}$ \\
\hline \multirow[t]{4}{*}{1} & \multirow{4}{*}{$\begin{array}{l}\text { Time spent using electronic } \\
\text { devices within } 24 \text { hours }\end{array}$} & between 1-3 hours per day & 8 \\
\hline & & 3-6 hours per day & 9 \\
\hline & & 6-12 hours per day & 15 \\
\hline & & 12 or more & 13 \\
\hline \multirow[t]{2}{*}{2} & \multirow[t]{2}{*}{ I watch pornographic sites } & YES & 34 \\
\hline & & $\mathrm{NO}$ & 11 \\
\hline \multirow[t]{2}{*}{3} & \multirow{2}{*}{$\begin{array}{l}\text { I do not mind communicating } \\
\text { with outsiders in the virtual } \\
\text { world, especially those who } \\
\text { admire their external } \\
\text { appearance }\end{array}$} & YES & 28 \\
\hline & & $\mathrm{NO}$ & 17 \\
\hline \multirow[t]{3}{*}{4} & \multirow[t]{3}{*}{ I use Microsoft Office } & YES & 8 \\
\hline & & $\mathrm{NO}$ & 11 \\
\hline & & $\begin{array}{c}\text { I don't know anything about } \\
\text { it }\end{array}$ & 26 \\
\hline \multirow[t]{2}{*}{5} & \multirow[t]{2}{*}{ The Internet is often used for } & $\begin{array}{c}\text { Entertainment, social } \\
\text { networking, and chatting }\end{array}$ & 35 \\
\hline & & Studying & 10 \\
\hline \multirow[t]{2}{*}{6} & \multirow{2}{*}{$\begin{array}{l}\text { I prefer to watch horror and } \\
\text { crime movies }\end{array}$} & YES & 37 \\
\hline & & $\mathrm{NO}$ & 8 \\
\hline \multirow[t]{2}{*}{7} & \multirow{2}{*}{$\begin{array}{l}\text { I do not mind meeting } \\
\text { strangers whom I met on the } \\
\text { Internet }\end{array}$} & YES & 28 \\
\hline & & $\mathrm{NO}$ & 17 \\
\hline \multirow[t]{2}{*}{8} & \multirow{2}{*}{$\begin{array}{l}\text { I consider owning a mobile } \\
\text { phone: }\end{array}$} & It is imperative and necessary & 31 \\
\hline & & This is not important to me & 14 \\
\hline
\end{tabular}

Source: Authors' own representation. 
The reliability of the questionnaire was tested using Cronbach's Alpha. The coefficient obtained was (,927). The results of the questionnaire show that, with regard to the first question, there is a relationship of statistical significance between the decline of educational, health and behavioral standards in children from educational institutions and the Information Revolution. Many studies have confirmed that the spread of technology has led to the provision of materials (pictures, movies or electronic games directed at adults or children) that expose violence among individuals in societies (Hanewald, 2008; Peterson, Densley, 2017). Young people are greatly affected by these mediatic outputs that expose violence in a direct or indirect manner, affecting their behavior.

The questionnaire indicates that 15 out of 45 of children spend between six and twelve hours a day using any given technological mean, as well as 34 out of 45 who visit porn sites, in addition to 37 out of 45 who prefer violent games and movies, which negatively affect their mental and physical health, leading to a change in their behavior and habits.

According to Bassam (2011) the number of Internet users is increasing daily. Many users reach the stage of addiction, becoming subject to family and health problems. This is exactly the case of the children from housing establishments, 35 out of 45 of whom prefer to use the Internet for entertainment. This is an indication of internet addiction, since only 10 out of 45 children use the Internet to study. Modern technology has made it easier to engage in behavior which is erroneous for weak and young persons, such as drug addiction. Technology sometimes isolates youth and allows them to escape reality by creating a virtual world, leading to innumerable problems. 31 out of the 45 study respondents are willing to do anything to get a mobile phone. There are cases registered with the police, about children who have stolen mobile phones. This draws attention to how vulnerable children are to the attractiveness of technology.

Focus group discussions revealed that knowledge of modern technologies owned by children in shelters is good and varied. These children have a high awareness of the dangers of social media and new technologies to their lives, yet they are not afraid to take on dangerous adventures because they do not care about these risks. In their opinion, they have nothing to lose compared to what they have already lost. When it came to IT\&C, the participants mentioned that they do not believe in its importance for science and education, but only in the material gains and entertainment that IT\&C provided. Respondents prefer to spend their time playing games and watching movies, and believe time allocated to use the Internet for such purposes should be unlimited. "Aims justify the means" is the principle that most of those children follow daily in their lives, even if sometimes they have to break the laws in order to reach their goals.

We have also found that there are educational methods based on modern technology that can help supervisors (and parents alike, where applicable) to correct the behavioral and educational problems experienced by most children of housing institutions.

Figure 1 shows that the majority of the studied institutionaluized children are addicted to technology, and the comparison with the results about the purpose of using the Internet becomes more evident through the Figures 2, 3 and 4. 
The research further reveiled that children lacked the foundations that would help them to improve their future with modern IT\&C technology. Instead, 34 out of 45 children watched pornographic movies. So, to address this danger through technology, we can only use some educational films about the risk of addiction to these sites and psychological guidance. It would be important to fill the spare time of these children with useful activities that have a positive impact on their mental and physical abilities.

Technology is able to help children receive a better education, so it is necessary to increase the number of 10 out of 45 that use technology to study by training the other children as well to use search engines and other applications, in order to increase their knowledge. 26 out of 45 children did not hear about the MS Office programs, and 11 out of 45 mentioned they will never use it. Since MS Office is one of the most important programs necessary to be acquainted with in order to find employment, several hours a week must be included to teach children how to use said programs.

Technology has advanced rapidly, and many other applications are also currently available to help children to study and to learn basic life abilities, as well as to provide them with global knowledge. These children are held back from benefiting from the advantages of IT\&C technology due to the absence of family and due the absence of professional and trained counselors to fill their basic educational needs.

Figure 1: Time spent using electronic devices within 24 bours

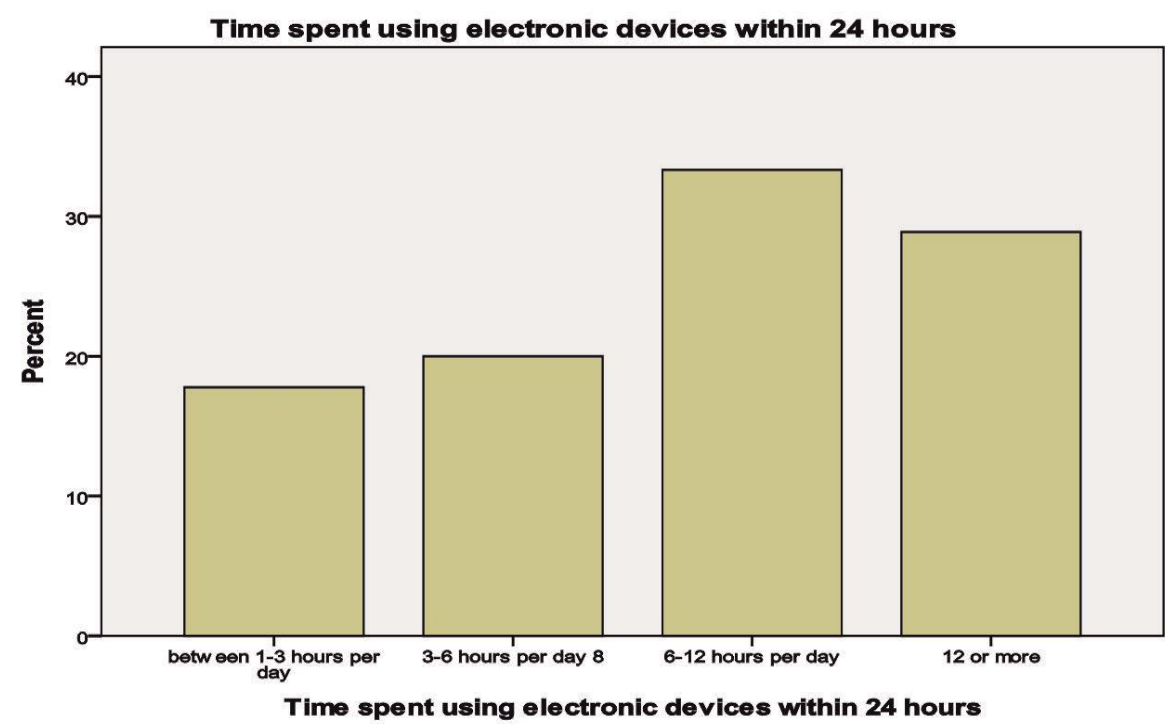

Source: Authors' own representation. 
Mona BĂDOI-HAMMAMI, Corina COLAREZA, Luciana MIHAI|105

Figure 2: Watching pornographic materials

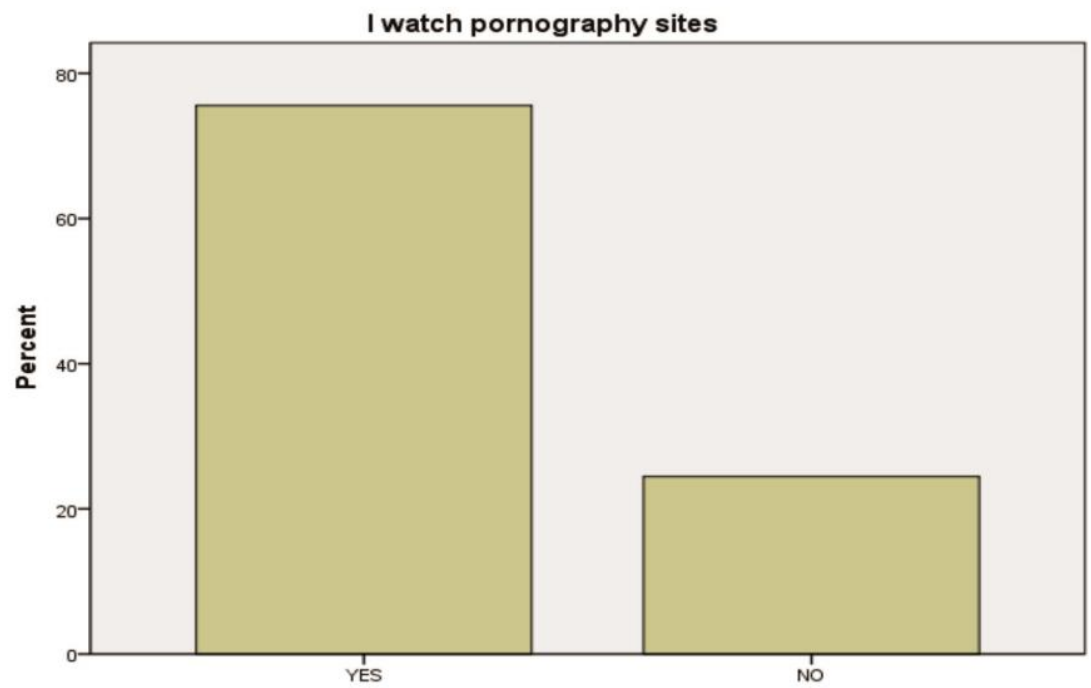

Source: Authors' own representation.

Figure 3: Use of Internet

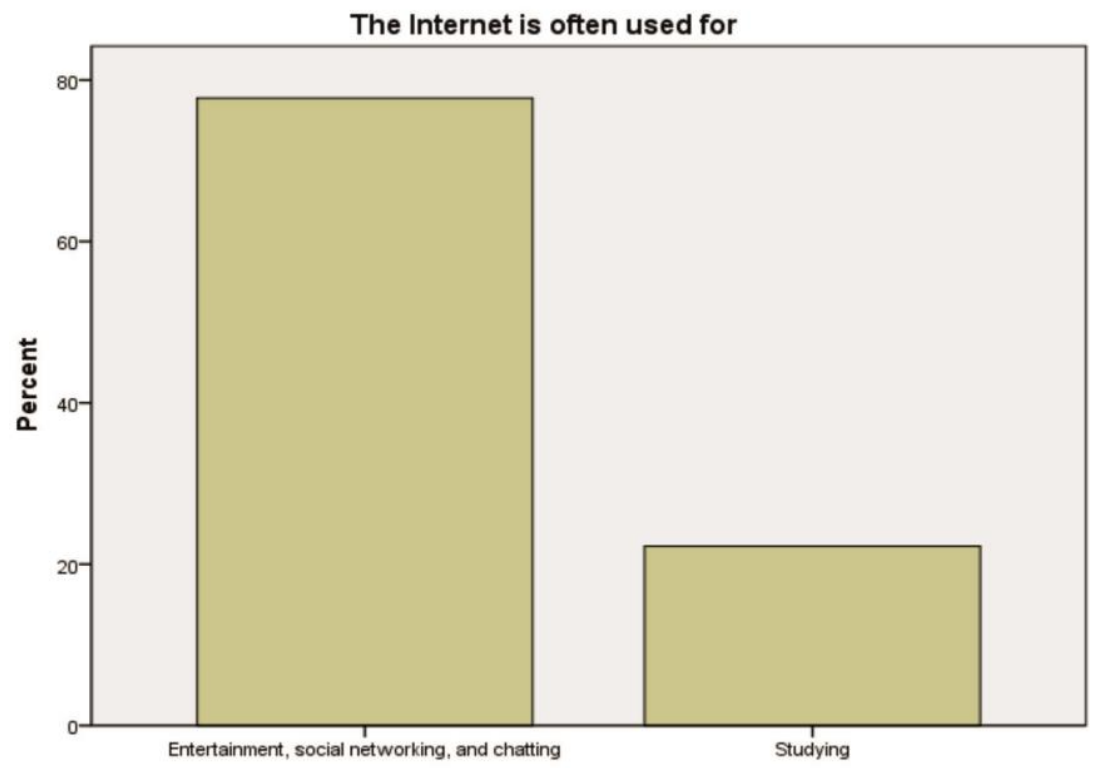

Source: Authors' own representation. 
Figure 4: Use of Microsoft Office

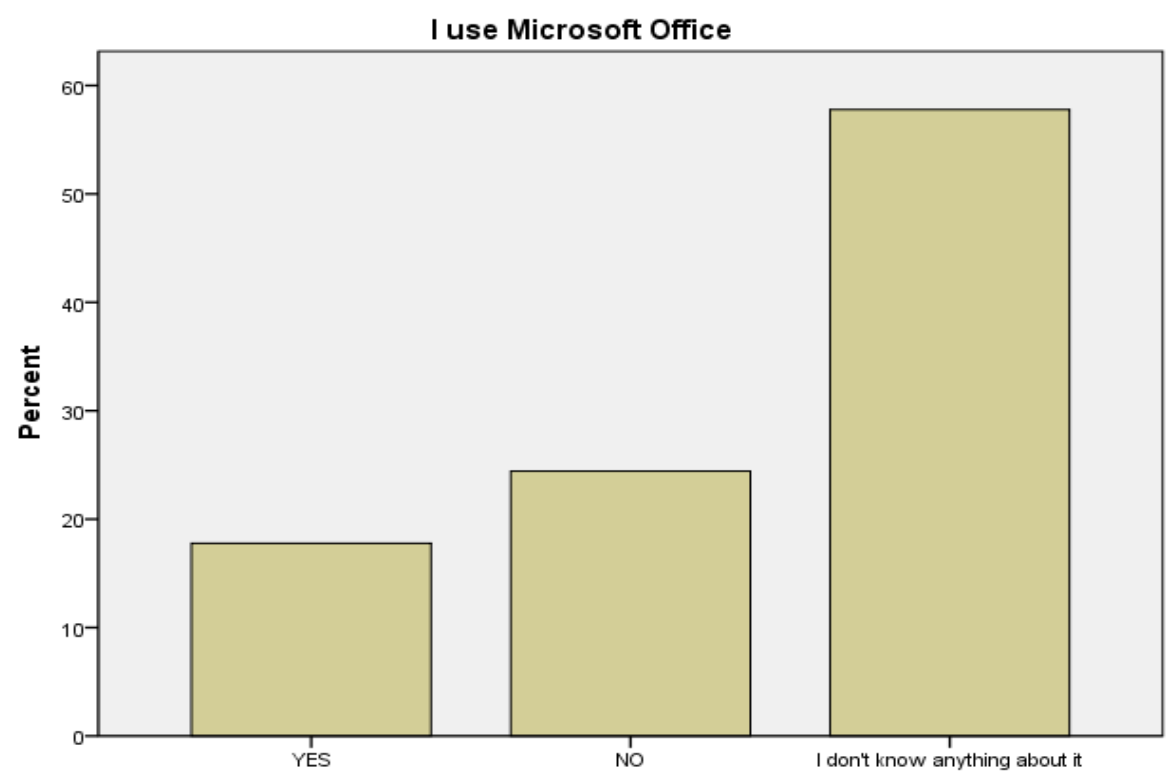

Source: Authors' own representation.

The interviews with the caregivers revealed that the IT\&C revolution has had at least some sort of negative impact on the institutionalized children, since most of them have broken a law at least once in order to get access to a mobile phone or to other modern gadgets. The caregivers confirmed the findings of the questionnaire by stating that, indeed, the time that the children spend on the Internet is mostly just for fun. Most of the caregivers said that they do not have ways to direct children towards the positive side of IT\&C. Caregivers also noticed an increase in violence and behavioral problems after the children became addicted to one of the technological means, especially upon losing one of those devices.

\section{Conclusions and recommendations}

Considering the findings of this research, the national social system should consider making some improvements so as to help institutionalized children benefit from the advantages of IT\&C technologies. The immediate and directly applicable interventions that one can think of are:

- Providing professional IT\&C training to social workers;

- Providing materials to children that contains messages to be delivered in order to modify a behavior, communicate an idea etc. The material which includes the 
message is displayed by video, short or long film, song etc. and reproduced by means of overhead projector, TV, computer etc. Multilateral interaction is necessary under the direct supervision of the caregiver, who has to be present in order to explain some points and direct the sessions towards their main purpose indirectly; the topics discussed should require interactive reaction by the children and a direct feedback when it is necessary to link the material to real life situations.

- The children should be directed to activities that help them organize their leisure time in a qualitative and efficient manner. Most importantly, it is necessary to involve them in activities of a familial nature.

\section{References}

Badrawi, H. (2003). Comparative Education. Cairo: Arab Nile Group.

Bassam, M.A.A. (2011). The negative effects of information technology on the family. Cairo: Dunia Al Watan.

Hanewald, R. (2008). Confronting the pedagogical challenge of cyber safety. Australian Journal for Teacher Education, 33(3), 1-16.

Odeh, J. (2013). Introduction to Advanced International Relations. Cairo: Arab Knowledge Office.

Peterson, J., \& Densley, J. (2017). Cyber violence: What do we know and where do we go from here?. Aggression and Violent Behavior, 34, 193-200. 